\title{
Differential expression of cell adhesion molecules in the functional compartments of lymph nodes and tonsils
}

\author{
R P Leite, M Carmo-Fonseca, J Cabeçadas, A Parreira, L Parreira
}

Institute of Histology and Embryology, Faculty of Medicine, University of Lisbon, Av. Prof. Egas Moniz, 1699 Lisboa Codex, Portugal

R P Leite

M Carmo-Fonseca

L Parreira

Portuguese Institute of Oncology, Av. Prof.

Lima Basto,

1093 Lisboa Codex,

Portugal

J Cabeçadas

A Parreira

Correspondence to:

Dr L Parreira.

Accepted for publication

20 December 1994

\begin{abstract}
Aims-To analyse the topographical distribution of adhesion molecules involved in lymphocyte recirculation in human lymph nodes and tonsils. The study focused on the expression of LECAM-1

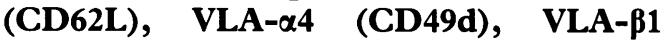
(CD29), LFA-1 $\alpha$ L (CD11a), LFA- $\beta 2$ (CD18), VCAM-1 (CD106), ICAM-1 (CD54), and H-CAM (CD44).
\end{abstract}

Methods-Reactive lymph nodes and palatine tonsils were studied using immunofluorescence methods with fluorescein isothiocyanate (FITC) labelled monoclonal antibodies directed against cell adhesion molecules. To investigate the expression patterns of these molecules in the $T$ and $B$ cell populations, double labelling experiments were performed using Texas Red labelled antibodies against CD2 or CD19, respectively. The images from each fluorochrome were then simultaneously analysed using a laser scanning confocal microscope.

Results-LECAM-1, VLA- $\alpha 4$ and H-CAM were predominantly expressed by mantle zone $B$ cells, VCAM-1 and ICAM-1 by germinal centre cells, most of which exhibited a reticular staining pattern suggestive of follicular dendritic cells, whereas LFA-1 $\alpha \mathrm{L}$ and LFA-B2 were mainly found in extrafollicular and germinal centre $T$ cells. All high endothelial venules expressed VLA- $\beta 1$ and ICAM-1, whereas VCAM-1 was present in only a few, with variable intensity.

Conclusions-The data show that all of these adhesion molecules are differentially distributed within the distinct functional microenvironments of both organs. The differences observed in the expression patterns among the $B$ and $T$ cells belonging to different compartments probably depend on the momentum of cell traffic, the stage of maturation/activation, as well as on their functional role in the immune response.

(f Clin Pathol: Mol Pathol 1995;48:M93-M100)

Keywords: Adhesion molecules, lymphocyte recirculation, lymph nodes, tonsils.

Most mature $\mathrm{B}$ and $\mathrm{T}$ lymphocytes continuously recirculate throughout secondary lymphoid organs in an exquisitely regulated and dynamic process. Naive $B$ and $T$ cells leave the primary lymphoid organs where they were generated, circulate in the blood and enter the secondary lymphoid organs across specialised high endothelial post-capillary venules (HEV). Later, they leave the lymphoid organs through the efferent lymph, drain into the blood, via the thoracic duct, and return to the same or another lymphoid organ. ${ }^{1}$ Although adhesion to $\mathrm{HEV}$ seems to be a general property of all mature lymphocytes, $\mathrm{B}$ and $\mathrm{T}$ cells exhibit a marked selectivity in their migration patterns to secondary lymphoid organs, a fact that will eventually determine the functional effector cell types that predominate in each particular organ. Mucosa associated lymphoid tissues are particularly enriched in B lymphocytes, in contrast to peripheral lymph nodes where $T$ cells make up more than two thirds of lymphoid cells. ${ }^{1}$ In addition to this organ specific distribution, $\mathrm{B}$ and $\mathrm{T}$ cells show distinct compartimentalisation within lymphoid tissues. Thus, after endothelial adhesion, B and T lymphocytes extravasate into the surrounding tissue and immediately segregate into different domains. Follicles are the predominant sites of B lymphocyte accumulation, while extrafolicular regions (interfollicular and paracortical regions in lymph nodes) are mainly populated by $\mathrm{T}$ lymphocytes. ${ }^{12} \mathrm{~A}$ corollary of this differential distribution is the creation of specialised microenvironments within the lymphoid tissue, which make up the scenario for the functional cell interactions that underlie the normal development of immune reactions. Thus, the entire follicles of unstimulated tissues (primary follicles) and the follicular mantle zone surrounding the germinal centre in stimulated organs (secondary follicles) are the sites where recirculating quiescent $\mathbf{B}$ lymphocytes seem to concentrate before further emigration, ${ }^{12}$ while interfollicular and paracortical regions form the environment for early activation of naive $B$ and $T$ cells by antigen. ${ }^{3-5}$ It is thought that activated $\mathrm{B}$ cells move to the germinal centre, where those that do not fulfil antigen specificity requirements die by apoptosis, while the others interact with follicular dendritic cells and helper $\mathrm{T}$ lymphocytes undergoing further proliferation and differentiation either into plasma cells or memory B cells. ${ }^{6}$ Memory cells, on the other hand, exhibit different traffic patterns when compared with naive cells. ${ }^{35}$ While the latter are able to extravasate across HEV into all secondary lymphoid organs, but not to non-lymphoid tissues, ${ }^{3}$ the former specifically home to the tissues where they first met the antigen and to their associated secondary 
lymphoid organs, ${ }^{3578}$ where they can be reactivated in extrafollicular areas. ${ }^{9}$

Lymphocyte recirculation, selective homing and functional tissue compartimentalisation are thus essential events for the normal function of the immune system. By their very nature, these phenomena suggest that the lymphoid cell can dynamically regulate adhesion and nonadhesion to other cells and to extracellular matrix components. Most relevant in this context are a number of molecules belonging to distinct protein families ${ }^{310-12}$ : LECAM-1 (selectin family), a protein that mediates the loose attachment of lymphocytes to HEV membrane oligosaccharides; VLA-4 and LFA-1, heterodimers of the $\beta-1$ and $\beta-2$ integrins, respectively, which are activation dependent proteins that promote strong and transient adhesion to $\mathrm{HEV}$ and also the diapedesis of lymphoid cells to the surrounding tissue; ICAM-1 and VCAM-1 (endothelial-cell ligands of LFA-1 and VLA-4, respectively), members of the immunoglobulin family of adhesion molecules; and H-CAM, a proteoglycan-like molecule which binds to hyaluronic acid in endothelial cells.

In this study we performed an integrated analysis of all these adhesion molecules in the distinct compartments of reactive human lymph nodes and tonsils. As these same molecules are thought to be involved in the dissemination of chronic lymphoproliferative disorders, ${ }^{7}$ the delineation of their distribution profiles in reactive lymphoid tissues is likely to provide useful information for the differential diagnosis of those conditions.

\section{Methods}

Six human palatine tonsils and six human lymph nodes (four cervical and two axillary) were analysed in this study. Lymph nodes were obtained from radical cervical or axillary lymph node dissection specimens from patients with laryngeal and breast carcinoma, respectively. All nodes were screened on haemotoxylin and eosin stained sections and non-metastatic lymph nodes were selected (size range: 5 to $10 \mathrm{~mm}$ ); in all samples there was histological evidence of tissue "reactivity" as assessed by the presence of large secondary follicles with a scarcely represented medullary compartment. ${ }^{13}$

The tissues were embedded in OCT compound (Miles Inc., Elkhart, Indiana, USA), snap frozen in liquid nitrogen and stored at $-80^{\circ} \mathrm{C}$. Cryosections $(7-10 \mu \mathrm{m}$ thick) were obtained with a Cryocut (Leica 1800). The sections were allowed to dry in air for two hours, were fixed in methanol for 10 minutes at $-20^{\circ} \mathrm{C}$, and were immersed in phosphate buffered saline (PBS) containing Tween $0.05 \%$ for five minutes. Tissue sections were then incubated with $1 \%$ normal human serum diluted in PBS for 10 minutes to block unspecific binding of antibodies to Fc receptors.

The primary monoclonal antibodies used in this study are listed in table 1 . For single labelling experiments, the sections were incubated with $6 \mu \mathrm{l}$ of each monoclonal antibody (undiluted) for 30 minutes at room temperature in a moist chamber. When antibodies conjugated with fluorescein isothiocyanate (FITC) were used, the sections were washed in PBS $(4 \times 5$ minutes) and mounted in glycerol/PBS (9:1) containing DABCO (triethylenediamine; Sigma, St Louis, Missouri, USA) as an antifading agent. In the case of non-conjugated antibodies the sections were washed in PBS $(4 \times 5$ minutes), incubated with FITC labelled goat antimouse IgG (Fab2 fragments; Vector Laboratories, Peterborough, UK) for $30 \mathrm{~min}-$ utes at room temperature in a moist chamber, washed in PBS ( $4 \times 5$ minutes) and mounted. In the case of biotin conjugated antibodies the sections were washed in PBS $(4 \times 5$ minutes and then sequentially incubated with Texas

Table 1 Characterisation of monoclonal antibodies used in the present study

\begin{tabular}{|c|c|c|c|c|c|c|c|}
\hline $\begin{array}{l}\text { Monoclonal } \\
\text { antibodies* }\end{array}$ & Conjugate & $\begin{array}{l}\text { Antigen cluster } \\
\text { designation }\end{array}$ & Clone & Isotype (species) & $\begin{array}{l}\text { Molecular } \\
\text { weight of the } \\
\text { antigen }\end{array}$ & $\begin{array}{l}\text { Main cellular expression } \\
\text { of the antigen }{ }^{1214} 15\end{array}$ & $\begin{array}{l}\text { Main site counteracting } \\
\text { with the antigen in the } \\
\text { adhesion process } \\
21415\end{array}$ \\
\hline Anti-LECAM-1 & FITC & CD62L & DREG56 & IgG1 (mouse) & $75-80 \mathrm{kDa}$ & $\begin{array}{l}\text { Lymphocytes, } \\
\text { monocytes, NK cells }\end{array}$ & $\begin{array}{l}\text { GlyCAM, CD } 34 \text {, } \\
\text { MadCAM-1 on } \\
\text { endothelial cells and } \\
\text { HEV }\end{array}$ \\
\hline Anti-VLA- $\alpha 4$ & None & CD49d & $\mathrm{HP} 2 \cdot 1$ & IgG1 (mouse) & $150 \mathrm{kDa}$ & $\begin{array}{l}\text { Monocytes, T and B } \\
\text { cells, Langerhans' cells }\end{array}$ & $\begin{array}{l}\text { VCAM-1 on activated } \\
\text { endothelial cells }\end{array}$ \\
\hline Anti-VLA $\beta 1$ & FITC & CD29 & $\mathrm{K} 20$ & IgG2a (mouse) & $130 \mathrm{kDa}$ & $\begin{array}{l}\text { Early haematopoietic } \\
\text { cells, T cells, } \\
\text { monocytes }\end{array}$ & Fibronectin and VCAM-1 \\
\hline Anti-VCAM-1 & None & CD106 & $1 \mathrm{G} 11$ & IgG1 (mouse) & $100-110 \mathrm{kDa}$ & $\begin{array}{l}\text { Activated endothelial } \\
\text { cells, FDC }\end{array}$ & VLA-4 on lymphocytes \\
\hline Anti-ICAM-1 & FITC & CD54 & $84 \mathrm{H} 10$ & IgG1 (mouse) & $90 \mathrm{kDa}$ & $\begin{array}{l}\text { Endothelial cells, many } \\
\text { cell types upon } \\
\text { activation }\end{array}$ & $\begin{array}{l}\text { LFA-1 and CD11b/ } \\
\text { CD18 }\end{array}$ \\
\hline Anti-LFA-1 $\propto \mathrm{L}$ & FITC & CD11a & $25 \cdot 3$ & IgG1 (mouse) & $180 \mathrm{kDa}$ & Leucocytes & $\begin{array}{l}\text { ICAM-1, ICAM-2, } \\
\text { ICAM-3 }\end{array}$ \\
\hline Anti-LFA- $\beta 2$ & FITC & CD18 & $7 \mathrm{E} 4$ & IgG1 (mouse) & $95 \mathrm{kDa}$ & Leucocytes & ICAM-1 \\
\hline Anti-H-CAM & FITC & CD44 & $J \cdot 173$ & IgG1 (mouse) & $80-90 \mathrm{kDa}$ & $\begin{array}{l}\text { Leucocytes and red } \\
\text { cells }\end{array}$ & Hyaluronate on HEV \\
\hline Anti-glycoprotein 90 & Biotin & CD19 & $\mathrm{B}-\mathrm{C} 3$ & IgG1 (mouse) & $90 \mathrm{kDa}$ & $\begin{array}{l}\text { Pan-B. Found at the } \\
\text { surface of FDC }\end{array}$ & - \\
\hline Anti-LFA-2 & Biotin & $\mathrm{CD} 2$ & $39 \mathrm{C} 1 \cdot 5$ & IgG2a (rat) & $50 \mathrm{kDa}$ & Pan-T & LFA-3 \\
\hline
\end{tabular}

* All monoclonal antibodies produced by Immunotech (Marseille, France) except for anti-GP90 (Serotec, Oxford, UK).

GlyCAM, glycosilation dependent cell adhesion molecule; MadCAM, Mucosal address in CAM; FDC, follicular dendritic cells; NK, natural killer. 
Table 2 Topography of adhesion molecules in human lymph nodes and tonsils

\begin{tabular}{|c|c|c|c|c|c|c|c|c|c|c|}
\hline \multirow[b]{2}{*}{ Molecule } & \multirow[b]{2}{*}{$C D$} & \multirow{2}{*}{$\frac{\text { Mantle zone }}{B \text { cells }}$} & \multicolumn{3}{|c|}{ Germinal centre } & \multicolumn{2}{|c|}{ Extrafollicular* } & \multicolumn{3}{|c|}{ Lymph node medullary cords } \\
\hline & & & $B$ cells & $T$ cells & $F D C$ & $B$ cells & $T$ cells & $B$ cells & $T$ cells & $H E V$ \\
\hline LECAM-1 & CD62L & +++ & - & $-1+$ & - & $-1+$ & $-1+$ & ++ & $-1+$ & - \\
\hline VLA- $x 4$ & CD 49d & +++ & $-1++$ & -++ & - & $-1+$ & $-1+$ & ++ & $-1+$ & - \\
\hline VLA- $\beta 1$ & CD29 & - & + & + & - & $-1+$ & $-1+$ & $-1+$ & $-1+$ & +++ \\
\hline VCAM-1 & CD106 & - & - & - & +++ & - & - & - & - & $+1++$ \\
\hline ICAM-1 & CD54 & - & $-1+$ & $-1++$ & +++ & $-1+$ & $-1+$ & ++ & $-1+$ & +++ \\
\hline LFA- $x 1$ & CD1la & - & - & +++ & - & - & ++ & - & ++ & - \\
\hline LFA- $\beta 2$ & CD18 & - & - & +++ & - & - & ++ & - & ++ & - \\
\hline H-CAM & CD44 & +++ & - & ++ & - & ++ & $-1+$ & ++ & $-1+$ & - \\
\hline
\end{tabular}

${ }^{*}$ Interfollicular and paracortical lymphocytes in the lymph node specimens. Interfollicular, sub- and intraepithelial lymphocytes in the tonsil tissue specimens.

FDC, follicular dendritic cells.

Staining intensity: - not detectable; + low ++ intermediate; +++ strong.

Red conjugated avidin $(1 \mu \mathrm{g} / \mathrm{ml}$; Vector Laboratories), mouse antiavidin $(5 \mu \mathrm{g} / \mathrm{ml}$; Vector Laboratories) and Texas Red conjugated avidin $(20 \mu \mathrm{g} / \mathrm{ml}$; Vector Laboratories). All sections were routinely post-fixed in $4 \%$ formaldehyde for 10 minutes before mounting.

Controls were created by omitting the primary antibody to ensure the specificity of the detection systems.

For double labelling experiments, the sections were first incubated with biotinylated anti-CD2 or anti-CD19, then biotin was detected using the avidin/antiavidin amplification system and finally the sections were incubated with FITC conjugated antibodies directed against adhesion molecules. As FITC conjugated antibodies were not available for VLA$\alpha 4$ and VCAM-1, we were forced to use nonconjugated ones. In this particular case, the sections were first incubated with non-conjugated antibody, then with FITC labelled goat antimouse IgG and finally, with the biotinylated antibody. Using this procedure, the staining pattern produced by each antibody was similar to that obtained in single labelling experiments.

To compare the differential expression of adhesion molecules in $\mathrm{B}$ and $\mathrm{T}$ cell populations directly, three sequential sections were used for the analysis of each adhesion molecule. The first was incubated with an antiadhesion molecule antibody, the second was double labelled for the adhesion molecule and B cells, and the third was double labelled for the adhesion molecule and $\mathrm{T}$ cells.

Samples were examined by the Zeiss LSM 310 confocal microscope. FITC and Texas Red images were acquired by excitation with the $488 \mathrm{~nm}$ argon ion laser and the $543 \mathrm{~nm}$ helium neon laser, respectively. For double labelling experiments, both fluorochromes were sequentially recorded in the same focal plane and pseudocolor images were generated and superimposed, as described previously. ${ }^{16}$

\section{Results}

Antibodies directed against cell adhesion molecules were used in both single and double immunofluorescence experiments with antiCD2, directed against thymocytes and mature $\mathrm{T}$ lymphocytes, ${ }^{14}$ and anti-CD 19 , directed against B cells, although it may also stain follicular dendritic cells. ${ }^{614}$

The staining patterns observed permitted clear delineation of the different compartments in both lymph nodes and tonsils (table 2), in terms of their adhesion molecule profiles, although some staining heterogeneity was evident either within the same sample or between different samples from both organs.

DISTRIBUTION OF LECAM-1

The antibodies against LECAM-1 stained most of the follicle mantle zone cells in both organs, whereas within germinal centres only a few cells were LECAM-1 positive (figs $1 \mathrm{~A}$ and $2 \mathrm{~A}$ ). Although most of the latter belong to the T lymphocyte subset, as assessed by colocalisation with $\mathrm{CD} 2$ (not shown), most of the germinal centre $T$ cells did not express LECAM-1. In extrafollicular cells (inter-follicular and paracortical regions in the lymph node, interfollicular and intraepithelial lymphoid tissue in the tonsil specimens), only a few $B$ and T cells were LECAM-1 positive as shown in double staining experiments with anti-CD19 (see interfollicular regions in fig 2A) and antiCD2 (not shown), respectively. In the lymph node medullary cords most cells stained positively with anti-LECAM-1. Most of these were also CD19 positive. Thus, LECAM-1 was detected predominantly in the $\mathrm{B}$ cell populations present in the follicular mantle in both organs and in the lymph node medullary cords.

\section{DISTRIBUTION OF VCAM-1}

VCAM-1, the endothelial ligand of VLA-4, was only detectable in the germinal centre cells (fig 1B) and in some HEV (fig 1J). In the germinal centres $T$ cells were VCAM-1 negative (not shown) and the morphological pattern was compatible with the staining of follicular dendritic cells, as shown in fig $1 \mathrm{~B}$. The intensity of HEV staining with anti-VCAM-1 varied within the same section, as shown in fig $1 \mathrm{~J}$.

\section{DISTRIBUTION OF VLA- $\alpha 4$ AND VLA- $\beta 1$}

VLA- $\alpha 4$ was detected in most mantle zones and medullary cord cells, and also in germinal centre and extrafollicular cells. The staining intensity with anti-VLA- $\alpha 4$ was generally high in the mantle zone and germinal centre cells compared with those of the extrafollicular regions (fig 1C). Both in the germinal centre and extrafollicular regions VLA- $\alpha 4$ co-localised 

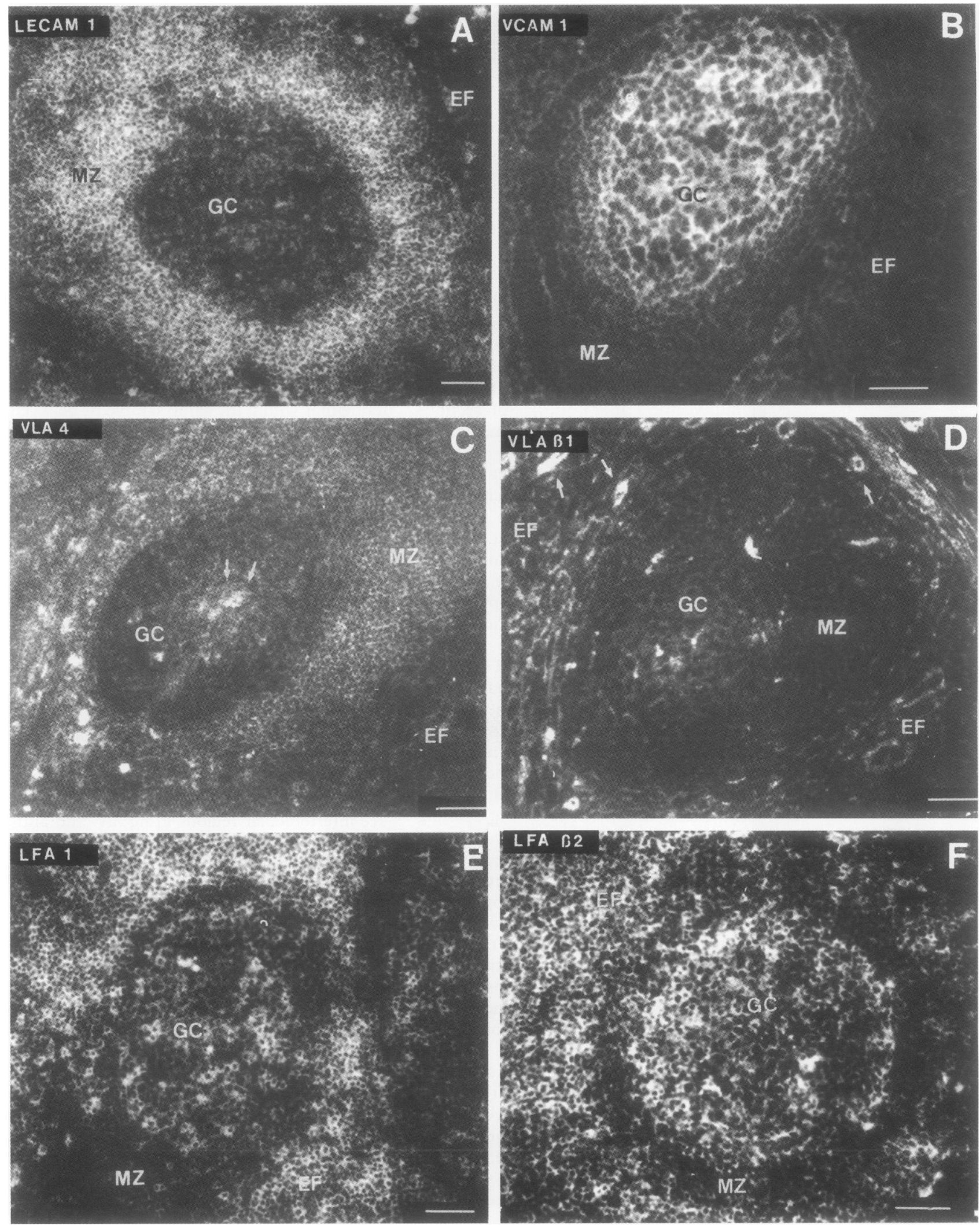

Figure 1 Distribution of adhesion molecules in human lymph nodes and tonsils. A: Detection of LECAM-1 in a lymph node follicle. The staining predominates in the mantle zone (MZ). Only a few cells in the germinal centre (GC) and extrafollicular regions (EF) were LECAM-1 positive. B: Detection of VCAM-1 in one tonsil follicle. Note the reticular pattern suggestive of follicular dendritic cells in the GC. C: Detection of VLA- 4 in a lymph node follicle. The staining is mainly restricted to the $M Z$. D: Detection of VLA- $\beta 1$ in the same follicle as depicted in $C$. Note the weak or absence of staining in the $M Z$, in contrast with $G C, E F$ cells and blood vessels (arrows). E: Detection of LFA-1 $\alpha L$ in a lymph node follicle. The staining was observed in a few GC cells and in most EF cells. F: Detection of LFA-B2 in a lymph node follicle. Staining was observed in most EF and GC cells. G. Detection of ICAM-1 in a lymph node follicle. The staining predominates in the GC and EF regions. $H$ : Detection of $H$-CAM in a lymph node follicle. The staining was observed predominantly in the $M Z$ region and in a few GC cells. Note the weak staining of the EF region. I: Detection of ICAM-1 in a high endothelial venule (HEV). $\mathcal{F}$ : Detection of VCAM-1 in HEV. Note different staining intensities for VCAM-1 in two distinct HEV (F, arrows). Bar $=50 \mu \mathrm{m}$.

with CD2 (fig 2B) or CD19 (not shown), indicating that $T$ and $B$ cells express this molecule. As shown by other authors, ${ }^{17} 18$ VLA$\alpha 4$ expression in the mantle zone cells largely exceeded that of the VLA- $\beta 1$ chain in terms of the staining intensity and the number of positive cells (figs $1 \mathrm{C}$ and 1D). This finding suggests that, in this region, the $\alpha 4$ chain of this integrin 

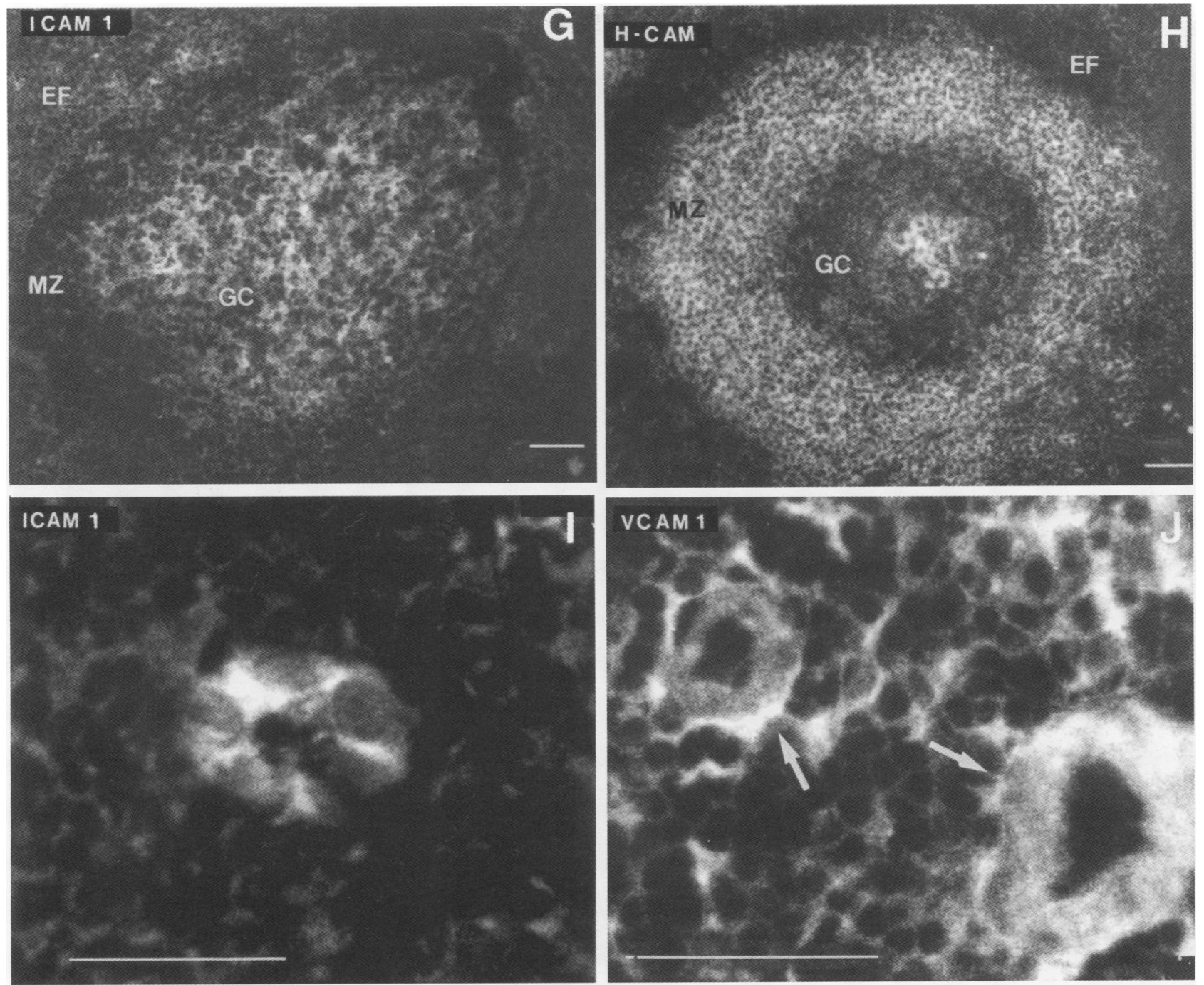

Figure 1-continued.

is not coupled with a $\beta 1$ chain. Anti-VLA$\beta 1$ antibody strongly stained all blood vessels, including $\mathrm{HEV}$, and the tonsillar crypt epithelium.

In summary, VLA- $\alpha 4$ seems to be expressed by $B$ and $T$ cells localised to all of the different lymphoid compartments in both organs, predominating within the mantle zone, germinal centres, and medullary cord cells, whereas VLA- $\beta 1$ is present in endothelial cells, in the tonsil epithelium and in extrafollicular B and $T$ cells, being almost absent in mantle zone cells.

DISTRIBUTION OF LFA- $1 \alpha$ L AND LFA- $\beta 2$

Both LFA- $1 \alpha$ L and LFA- $\beta 2$ were detected in extrafollicular and germinal centre cells (figs $1 \mathrm{E}$ and $1 \mathrm{~F}$ ), where they co-localised with $\mathrm{CD} 2$, showing that $\mathrm{T}$ cells in both of these regions are the predominant cell population expressing this integrin heterodimer. Most medullary cord cells in the lymph nodes weakly expressed LFA- $1 \alpha \mathrm{L}$ or were negative. All blood vessels were strongly positive on staining with antiLFA- $\beta 2$ antibody.

\section{DISTRIBUTION OF ICAM-1}

Staining for ICAM-1 was present in almost all blood vessels (see HEV in fig 1I), in the lymph node medullary cord and germinal centre cells (fig 1G), and also in a few cells of the extrafollicular regions. In the lymph node medullary cords staining with anti-ICAM-1 colocalised with CD19, whereas in germinal centre and extrafollicular region cells there was a predominant but not exclusive co-localisation with the $T$ cell marker (CD2) (fig 2D). In germinal centre cells the co-localisation of ICAM-1 with CD19 mainly exhibited the typical reticular pattern suggestive of follicular dendritic cells (fig 2C). Thus, ICAM-1 seems to be predominantly expressed by endothelial cells, medullary cord B cells in lymph nodes, extrafollicular and germinal centre $T$ cells, and also by follicular dendritic cells.

\section{DISTRIBUTION OF H-CAM}

This molecule was detected predominantly in the mantle zone cells in both organs (fig $1 \mathrm{H}$ ). In the germinal centres H-CAM positive cells seemed to be restricted to a part of the $T$ cell population (fig $2 \mathrm{~F}$ ), while most CD19 positive cells (B cells and follicular dendritic cells) were $\mathrm{H}-\mathrm{CAM}$ negative (fig 2E). Staining with anti$\mathrm{H}-\mathrm{CAM}$ was weaker in paracortical and medullary cord cells than in the mantle zone cells, mostly co-localising with CD19. T cells (CD2 



Figure 2 Distribution of adhesion molecules in human lymph node follicles relative to $B$ and $T$ cell populations. Tissue sections were double labelled with antibodies directed against adhesion molecules and the pan-B (CD19) or the pan-T (CD2) antibodies, conjugated with different fluorochromes (red and green staining). Confocal images from each fluorochrome were recorded and superimposed. Co-localisation of the two fluorochromes is demonstrated by a yellowish color. A: CD19 (red) and LECAM-1 (green). Both molecules co-localise in the MZ region (yellow). B: CD2 (green) and VLA-x4 (red). Both molecules co-localise in some GC and EF cells (yellow). C: CD19 (red) and ICAM-1 (green). The GC shows co-localisation (yellow) of both molecules in a pattern suggestive of follicular dendritic cells. D: CD2 (red) and ICAM-1 (green). Co-localisation of CD2 with ICAM-1 (yellow) was found in many EF cells and in some GC cells. E: CD19 (red) and H-CAM (green). The co-localisation (yellow) of both molecules was found predominantly in the $M Z$ cell population. F: CD2 (red) and H-CAM (green). Co-localisation was observed in EF cells and GC cells (yellow). Bar $=50 \mu \mathrm{m}$. 
positive) were heterogeneously stained with anti-H-CAM in all extrafollicular regions.

Thus, H-CAM is predominantly detectable in the mantle zone, extrafollicular and medullary cord B cells and also in some germinal centre $\mathrm{T}$ cells.

\section{Discussion}

In this study we provide an integrated view of the distribution of cell adhesion molecules in the distinct functional compartments of reactive human lymph nodes and tonsils.

To enter the extravascular space in a peripheral lymphoid organ, circulating lymphocytes must interact with specific molecules present in the plasma membrane of endothelial cells. ${ }^{12}$ Two well characterised endothelial adhesion molecules are ICAM-1 and VCAM-1, both members of the immunoglobulin superfamily. ${ }^{3}$ ICAM- 1 is constitutively expressed in the membrane of all endothelial cells, ${ }^{19}$ whereas VCAM-1 is upregulated during endothelial cell activation. ${ }^{2021}$ This is consistent with the observation that antibodies against ICAM-1 stained all blood vessels, while anti-VCAM-1 antibodies stained some but not all HEV. As anti VCAM-1 antibodies are likely to label only activated endothelial cells, this may indicate that endothelial activation is not a synchronous phenomenon in lymphoid organs.

ICAM-1 and VCAM-1 from endothelial cells bind to LFA-1 and VLA-4, respectively, on lymphocytes. ${ }^{31719}$ The interactions between these molecules on both cell types mediate a strong, albeit transient, adhesion of lymphoid cells to the endothelium. ${ }^{12}$ Upon adhesion of a lymphocyte to the endothelium, VLA-4 is functionally activated and upregulated and participates, together with the ICAM-1/LFA-1 pathway, in the process of diapedesis and chemotaxis of lymphocytes into the surrounding tissue. $^{3622}$ Therefore, the staining produced by anti-VLA- $\alpha 4$ antibodies in the mantle zone and extrafollicular regions is likely to reflect the migratory behaviour of the cells present within these compartments.

In addition to endothelial cells, the follicular dendritic cells in germinal centres also express ICAM-1 and VCAM- ${ }^{10}$ which interact with LFA-1 and VLA-4, respectively, expressed by germinal centre B cells. ${ }^{63}$ The contact between follicular dendritic cells and B lymphocytes is crucial for the terminal activation and differentiation phenomena that underlie the generation of effector and memory $B$ cells in germinal centres. ${ }^{623}$ Accordingly, we observed that germinal centres were labelled by antibodies directed against ICAM-1, VCAM-1, LFA1- $\alpha$ L, and VLA- $\alpha 4$.

ICAM- 1 is expressed by endothelial and follicular dendritic cells, and also by $T$ and $B$ lymphocytes upon cell activation. ${ }^{19}$ Therefore, the extrafollicular ICAM-1 positive cells that co-express CD2 probably represent activated T lymphocytes. However, ICAM-1 is also involved in $\mathrm{T}$ cell dependent $\mathrm{B}$ cell activation, via the ICAM-1/LFA-1 pathway, ${ }^{19}$ and thus activated $B$ cells may also account for the extrafollicular and medullary cord staining ob- served. The lack of ICAM-1 labelling in the mantle zone B cells is consistent with the quiescent state of these cells. ${ }^{9}$

LFA-1, the counter-receptor of iCAM-1, was detected in the same compartments as ICAM-1 - that is, germinal centres and extrafollicular regions, but not in HEV. Most of the LFA1- $\alpha \mathrm{L}$ positive cells co-expressed CD2 in both compartments, showing that this molecule is mainly present in $T$ cell populations. This finding agrees with the observation that LFA-1, despite being expressed by all leucocytes and some macrophages, is more abundantly expressed on $\mathrm{T}$ than on $\mathrm{B}$ cells, and is present at higher concentrations in activated T cell blasts. ${ }^{24}$ However, it is known that isolated germinal centre $B$ cells also express this molecule and, as previously mentioned, the ICAM-1/LFA-1 pathway participates in follicular dendritic cell/B lymphocyte binding and in the generation of B memory cells in the germinal centres. ${ }^{623}$ In this study, co-localisation of CD19 and LFA-1 $\alpha \mathrm{L}$ was found in a few germinal centre cells. As isolated follicular dendritic cells seem to be LFA-1 negative, ${ }^{6}$ it is likely that the CD19/LFA-1 $\alpha \mathrm{L}$ positive cells represent activated germinal centre $\mathrm{B}$ lymphocytes.

The selectin LECAM-1 is expressed by most mature and recirculating naive $B$ and $T$ lymphocytes. ${ }^{7}$ We observed that the mantle zone was the most intensely labelled compartment with antibodies against LECAM-1. This finding is consistent with the hypothesis that this region is mostly populated by quiescent B cells. ${ }^{9}$ As LECAM-1 is present in mature circulating cells and mediates a loose and transient attachment to the $\mathrm{HEV},{ }^{3}$ one can speculate that the persistance of LECAM-1 in the mantle zone cells reflects their recirculating behaviour. Likewise, those extrafollicular cells that were LECAM-1 positive and co-expressed either CD2 or CD19 probably represent naive $T$ and $B$ cells that have just exited the HEV. However, many extrafollicular lymphocytes were LECAM-1 negative, a finding that can be interpreted as indirect evidence that these cells might belong to an early activated subset. This assumption is based on the knowledge that extrafollicular regions are the sites where naive cells are primed by antigen ${ }^{5}$ and that cell activation is followed by downregulation and membrane shedding of LECAM-1. ${ }^{25}$ This would further explain the paucity of LECAM-1 expression in germinal centre lymphoid cells which, apart from being sessile in nature, are mostly in an activated state. ${ }^{6}$ Although LECAM-1 is considered to be a homing receptor for peripheral lymph nodes and not for mucosa associated lymphoid tissues, ${ }^{3}$ it must be noted that no obvious differences were observed in its regional distribution, both in lymph nodes and tonsils. This observation might be due to the fact that tonsils behave, in terms of lymphocyte homing, more like a peripheral tissue and that the LECAM-1 ligand is expressed at high concentrations in tonsilar HEV. $^{26}$

Like LECAM-1, the proteoglycan-like molecule H-CAM was mostly detected in 
mantle zone cells, although the majority of extrafollicular and medullary cord B cells and a minority of extrafollicular and germinal centre $\mathrm{T}$ cells also stained weakly with anti-H-CAM antibodies. H-CAM is expressed by the majority of mature circulating lymphocytes and is known to be present at higher concentrations in virgin B cells than in those that have been primed by antigen. ${ }^{27}$ Thus, H-CAM expression in tissue lymphocytes is likely to reflect both its role in regional migratory events and its activation dependent variations. Consistent with this assumption, we observed that (1) the quiescent and recirculating mantle zone $B$ cells stained more strongly with anti-H-CAM than extrafollicular B cells, many of which, although still mobile, are in an early-activated state ${ }^{5} ;(2)$ the activated and sessile germinal centre $B$ cells were negative for H-CAM. Likewise, different degrees of cell activation and/or mobility may explain the heterogeneity of H-CAM expression observed within the $\mathrm{T}$ cell subsets in each compartment.

In summary, we conclude that adhesion molecules are differentially distributed in the distinct functional compartments of both lymph nodes and tonsils. Within each compartment, the expression patterns observed in the different cell populations seem to reflect the functional involvement of adhesion molecules both in lymphocyte trafficking and in the cell to cell interactions that take place in the specialised lymphoid microenvironments.

This study was supported by a grant from Junta Nacional de Investigação Científica e Tecnológica (JNICT-1542/92) and RPL by a JNICT fellowship.

1 Rouse RV, Reichert RA, Gallatin WM, Weissman IL, Butcher EC. Localization of lymphocyte subpopulations in peripheral lymphoid organs: directed lymphocyte migration and segregation into specific microenvironments. Am $\mathcal{A}$ Anat 1984;170:391-405.

2 Stein H, Gerdes J, Mason DY. The normal and malignan germinal center. Clin Haematol 1982;11:531-59.

3 Picker LJ, Butcher EC. Physiological and molecular mechanisms of lymphocyte homing. Ann Rev Immunol 1992, anisms of lym

4 Sprent J. T and B memory cells. Cell 1994;76:315-22.

5 Springer TA. Traffic signals for lymphocyte recirculation and leukocyte emigration: the multistep paradigm. Cell and leukocyte emig

6 Koopman G, Pals S. Cellular interactions in the germinal center: role of adhesion receptors and significance for the pathogenesis of AIDS and malignant lymphoma. Immunol $\operatorname{Rev} 1$ 992:126:21-45.

7 Pals ST, Horst E, Scheper RJ, Meijer CJLM. Mechanisms of human lymphocyte migration and their role in the pathogenesis of disease. Immunol Rev 1989;108:111-33.

8 Butcher EC. Leucocyte-endothelial cell recognitions: three (or more) steps to specificity and diversity. Cell 1991;67 1033-6.

9 Moller P, Eichelmann A, Koretz K, Mechtersheimer G Adhesion molecules VLA-1 to VLA-6 define discrete stages of peripheral B lymphocyte development and characterize different types of B cell neoplasia. Leukemia 1992; 6:256-64.

10 Pringer TA. Adhesion receptors of the immune system. Nature 1990;346:425-33.

11 Shimizu Y, Shaw S. Lymphocyte interactions with extracellular matrix. FASEB f 1991;5:2292-9.

12 Ager A. Lymphocyte recirculation and homing: roles of adhesion molecules and chemoattractants. Trends Cell Biol 1994;4:326-32

3 Van der Valk P, Meijer CJLM. The histology of reactive lymph-nodes. Am $\mathcal{f}$ Surg Pathol 1987;11:866-82.

14 Leococyte Typing IV. White Cell Differentiation Antigens. Knapp W, Dorken D, Gilks WR, Rieber EP, Schmidt RE, Stein $\mathrm{H}$, et al, eds. Oxford: Oxford University Press, 1989.

15 Pinto A, Gattei V, Soligo D, Parravicini C, Vecchio LD. New molecules burst at the leukocyte surface. A comprehensive molecules burst at the leukocyte surface. A comprehensive review based on the 5 th International Workshop on leu-

16 Carmo-Fonseca M, Tollervey D, Pepperkok R, Barabino SML, Merdes A, Brunner C, et al. Mammalian nuclei contain foci which are highly enriched in components of the pre-mRNA splicing machinery. EMBO $\mathcal{f} 1991 ; 10$ : 195-206.

17 Hemler ME. VLA proteins in the integrin family: structures, functions, and their role on leukocytes. Ann Rev Immunol 1990;8:365-400.

18 Zutter MM. Immunolocalization of integrin receptors in normal lymphoid tissues. Blood 1991;77:2231-6.

19 Maio M, Vecchio LD. Expression and functional role of CD54/intracellular adhesion molecule 1 (ICAM-1) on human blood cells. Leuk Lymphomol 1992;8:23-33.

20 Issekutz TB. Lymphocyte homing to sites of inflammation. Curr Opin Immunol 1992;4:287-93.

21 Shimizu Y, Newman W, Yoshiya T, Shaw S. Lymphocyte interactions with endothelial cells. Immunol Today 1992; 13:106-13.

22 Hynes RO. Integrins: versability, modulation, and signaling in cell adhesion. Cell 1992;69:11-25.

23 Koopman G, Parmentier HK, Schuurman H-J, Newman W, Meijer CJL, Pals ST. Adhesion of human B cells to follicular dendritic cells involves both the lymphocyte function-associated antigen 1/intracellular adhesion molecule 1 and very late antigen $4 /$ vascular cell adhesion molecule 1 pathways. F Exp Med 1991;173:1297-304.

24 Springer TA, Dustin ML, Kishimoto TK, Marlin SD. The lymphocyte function-associated LFA-1, CD2, and LFA3 molecules: cell adhesion receptors of the immune system. Ann Rev Immunol 1987;5:223-52.

25 Kishimoto TK, Jutila MA, Butcher EC. Identification of a human peripheral lymph-node homing receptor: a rapidly down-regulated adhesion molecule. Proc Natl Acd Sci USA 1990;87:2244-8.

26 Picker LJ, Treer JR, Ferguson-Darnell B, Collins PA, Buck D, Terstappen LWMM. Control of lymphocyte recirculation in man. I. Differential regulation of the peripheral lymph-node homing receptor L-selectin on T cells during the virgin to memory cell transition. 7 Immunol during the virgin to

27 Horst E, Meijer CJLM, Radaskiewskz T, Van Dongen JJM, Pieters R, Figdor CG, et al. Expression of a human homing receptor (CD44) in lymphoid malignancies and related stages of lymphoid development. Leukemia 1990;4:383-9. 